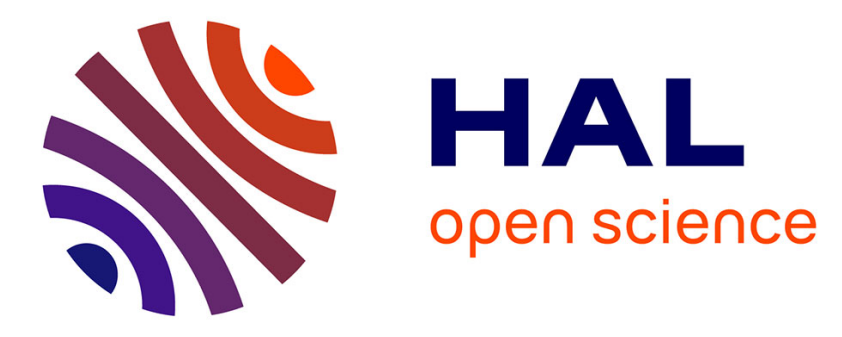

\title{
Micromechanical local approach to brittle failure in bainite high resolution polycrystals: A short presentation
}

Can Ngon Nguyen, Fabrice Barbe, Nikolay Osipov, Georges Cailletaud, Bernard Marini, C. Petry

\section{To cite this version:}

Can Ngon Nguyen, Fabrice Barbe, Nikolay Osipov, Georges Cailletaud, Bernard Marini, et al.. Micromechanical local approach to brittle failure in bainite high resolution polycrystals: A short presentation. Computational Materials Science, 2012, 64, pp.62-65. 10.1016/j.commatsci.2012.03.034 . hal-00732433

HAL Id: hal-00732433

https://hal-mines-paristech.archives-ouvertes.fr/hal-00732433

Submitted on 1 Sep 2020

HAL is a multi-disciplinary open access archive for the deposit and dissemination of scientific research documents, whether they are published or not. The documents may come from teaching and research institutions in France or abroad, or from public or private research centers.
L'archive ouverte pluridisciplinaire HAL, est destinée au dépôt et à la diffusion de documents scientifiques de niveau recherche, publiés ou non, émanant des établissements d'enseignement et de recherche français ou étrangers, des laboratoires publics ou privés. 


\title{
Micromechanical local approach to brittle failure in bainite high resolution polycrystals: a short presentation
}

\author{
C.N. N'Guyen ${ }^{\mathrm{a}}$, F. Barbe ${ }^{\mathrm{b}, *}$, N. Osipov ${ }^{\mathrm{a}}$, G. Cailletaud ${ }^{\mathrm{a}}$, B. Marini ${ }^{\mathrm{c}}$, C. Petry $^{\mathrm{d}}$ \\ ${ }^{a}$ Mines Paristech, Centre des Matériaux, CNRS UMR 7633 \\ 91003 Evry, France \\ ${ }^{b}$ INSA Rouen, Groupe de Physique des Matériaux, CNRS UMR 6634 \\ 76801 Saint Etienne du Rouvray, France \\ ${ }^{c} C E A, D E N$, SRMA, 91191 Gif sur Yvette, France \\ ${ }^{d} E D F R \& D, D M M C$, Les Renardières, 77818 Moret sur Loing, France
}

\begin{abstract}
The problem of determining the probability of failure in a brittle material from a micromechanical local approach has recently been addressed in few works ([3; 4; 2]), all related to bainite polycrystals at different temperatures and states of irradiation. They have separately paved the ground for a full-field modelling with high realism in terms of constitutive modelling and microstructural morphology. This work first contributes to enhance this realism by assembling the most pertinent/valuable characteristics (dislocation density based model, large deformation framework, fully controlled triaxiality conditions, explicit microstructure representation of grains and sub-grains, ...) and by accounting for a statistically representative Volume Element; this condition indeed must be fulfilled in order to capture rare events like brittle micro-fractures which, in the stress analysis, correspond to the tails of distribution curves. The second original contribution of this work concerns the methodology for determining fracture probabilities: rather than classically -and abruptably-considering a polycrystal as broken as soon as an elementary link (grain or sub-grain) has failed, the possibility of microcrack arrest at microstructural barriers is introduced, which enables to determine the probability of polycrystal failure according to different scenarii of multiple micro-fractures.

Key words: Brittle failure, Micromechanical local approach, Polycrystals, Microstructural barriers

\section{Introduction}

Low alloy bainitic steels are widely used in nuclear industry. A comprehensive and reliable prediction of their resistance and life-time has to account for the corresponding conditions of service: a wide range of temperatures combined with the exposure to neutron radiation. The temperature acts on the dislocation mechanisms which take

*Corresponding author, tel: 332329597 60, fax: 33232959704

Email addresses: ngon_11_nguyencan@yahoo.com (C.N. N'Guyen), fabrice.barbe@insa-rouen.fr (F. Barbe), nikolay.osipov@ensmp.fr (N. Osipov), georges.cailletaud@ensmp.fr (G. Cailletaud), bernard.marini@cea.fr (B. Marini), charles.petry@edf.fr (C. Petry)
\end{abstract}


place for accomodating stresses whereas radiation causes the formation of defects (interstitial loops, void clusters and precipitates). One has thus to face with the problem of interacting dislocations and defects within a highly heterogeneous crystalline material for predicting hardening and embrittlement which are directly related to failure probability.

Following several developments of microstructure and dislocation density based models dedicated to the plastic behaviour and brittle failure of low carbon bainitic steels [3; 4; 2], the present work (after [9]) proposes to extend the modelling by combining several points that have been already considered: (i) microstructures with enhanced realism in terms of crystal orientations, morphology, size and statistical representativity, (ii) dislocation density based constitutive laws and (iii) large deformation framework.

A full-field approach (section 2) has been applied to the case of bainite polycrystals subjected to particular triaxiality conditions at different temperatures. The resulting deformation and stress fields are post-processed in order to determine probabilities of failure according to a new "micromechanical local approach" (section 3). With this qualification, it is meant that the approach accounts for micromechanical fields (from which microcracks activity can be predicted within either grains or subgrains of the microstructure) for determining the probability of crack propogation within a material element located at the crack tip of a CT specimen. As regards the classical weakest link approach which postulates a straightforward fracture as soon as a sub-domain (grain or sub-grain) is broken, our approach offers the possibility to describe/predict the polycrystal failure according to different scenarii of microfractures, where microcracks can be arrested at microstructural barriers or propagate.

\section{Full-field modelling}

Low alloy bainitic steels are meant to provide particular mechanical performances over a wide range of temperatures. Their chacteristics, as regards other steels, can be related to the high complexity of their microstruture, featuring different phases (cementite, ferrite) and entities (precipitates, laths, packets, grains...) at different scales. For the sake of accuratly modelling local interactions between these entities, which are at the origin of high local cleavage stresses, the analyses performed in [2, 3] have allowed to establish the main characteristics of the microstructure that have to be accounted for: an explicit representation of primary austenite grains and bainite packets within each primary grain, a mean representation of the laths constituted by a homogeneous mixture of ferrite laths and cementite precipitates (which is justified by the fact that misorientations between laths of a same packet are small), and a random distribution of carbides within packets which are considered for determining local fracture probabilities. Furthermore, the crystallographic orientations of the bainite packets have to respect relationships of the type Kurdjumov-Sachs (KW) or NishiyamaWassermann $(\mathrm{NW})$ w.r.t. primary austenite grains orientations. It has also been observed $\gg$ in $[1,2]<<$ that the determination of packet-to-packet local interactions were particularly mesh sensitive and that consequently, packets interfaces should $(i)$ be flat for the sake of realism and (ii) strictly conform elements boundaries in order to exclude discretization effects.

In the continuation of previous works $([3 ; 4,2])$, this study addresses the problem of failure probability in a Volume Element (VE) which has to be representative 


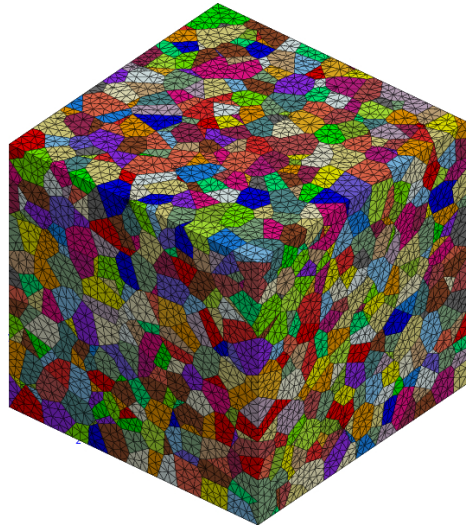

(a)

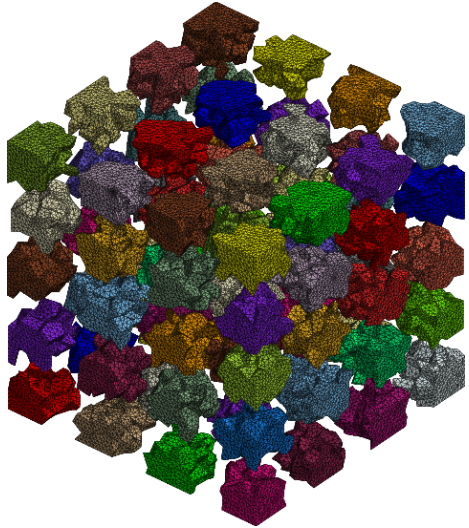

(b)

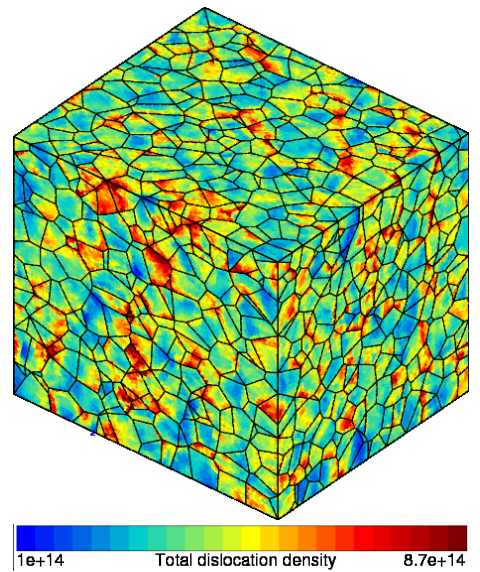

(c)

Figure 1: Unstructured mesh of a 4096-cell Voronoi mosaic representing a bainite polycrystal: 670000 nodes, 500000 ten-node tetrahedral elements, 27 sub-domains for parallel computations. (a) each Voronoi cell is a bainite packet; (b) exploded view of the primary austenitic grains, constituted by 50 packets on average; (c) contour plot of the total dislocation density for $10 \%$ plane strain tension.

morphologically as well as statistically. Prevailing to this latter condition, both the number of primary austenite grains and the mean number of packets per grain must be large enough. Here, 50 packets per grain -in average- and 80 primary grains have been used. $\gg$ This largely ensures the representativity of the polycrystal w.r.t. effective properties or mean responses per packet in a bulk polycrystal. Concerning packet orientations and boundary misorientations, which are respectively involved in cleavage fracture occurrences and microcrack deviations or arrests at packet boundaries [5], the statistical representativity remains tentative at this state of the study. Supplementary analyses on other realisations of polycrystals or on a larger polycrystal would bring out answers on this issue. 44 As shown in fig. 1, it has been chosen to model packets with cells of a Voronoi mosaic (4096 cells presently). Cells are then assembled to form primary austenite grains. The software package Neper [10] is used for generating the microstructure and the unstructured mesh $\gg$ (ten-node tetrahedral elements) $\triangleleft 4$, with particular care about the quality of the elements and the refinement around interfaces.

This study aims at predicting the probability of failure of a BCC material at different temperatures and should thus account for the principal mechanisms involved in such materials: thermally activated dislocations, double kink formation, preferential activation of such or such slip system family $(<110>\{111\}$ or $<112>\{111\})$. The chosen constitutive laws, inspired from the works of Kocks, Rauch and Tabourot, result from the combination of different models which has been presented in [4: 9]: the temperature dependent flow rule (eq. 1) describes the slip on each slip system through an activation energy depending on the shear stress; the hardening rule on a slip system (eq.2) is deduced from its dislocation density and that of other slip systems; the dislocation density is related to the slip rate, the mean free path and the critical distance of annihilation (eq. 3).

$$
\dot{\gamma}^{s}=\dot{\gamma}_{0} \exp \left[-\frac{\Delta G_{0}}{k_{B}} T\left(1-\left(\frac{\left|\tau_{\text {eff }}^{s}\right|}{\tau_{R}}\right)^{p}\right)^{q}\right] \operatorname{sign}\left(\tau^{s}\right)
$$




$$
\begin{gathered}
\tau_{e f f}=\tau^{s}-\tau_{0}-\tau_{\text {int }}^{s} \quad ; \quad \tau_{\text {int }}^{s}=\frac{(\mu b)^{2} \sum_{u \neq s} a^{s u} \rho^{u}}{\tau^{s}-\tau_{0}} \\
\dot{\rho}^{s}=\frac{\left|\dot{\gamma}^{s}\right|}{b}\left(\frac{1}{D_{\text {grain }}}+\frac{\sqrt{\sum_{u \neq s} \rho^{u}}}{K(T)}-g_{c}(T) \rho^{s}\right)
\end{gathered}
$$

The equations are written in a finite strain framework with a multiplicative decomposition of the displacement gradient. Simulations are performed on a parallel supercomputer with the software Zset (zset-software.com, MINES ParisTech, ONERA - the French Aerospace Lab, NW Numerics \& Modeling, Inc, [11]).

The parameters that could not be set according to physical observations have been identified for different temperatures by comparison to experimental tensile stress-strain curves at large strain (14\%). To this purpose, the full parameter space has first been automatically explored by using a simplified FE polycrystal (343 grains, 1 hexahedral element per grain), then, in a second step, parameter identification has been refined with a more representative VE (1000 Voronoi cells, 1 to 50 cells per primary austenite grain, random or KS or NW orientation relationships, unstructured mesh with 75000 tetrahedral elements).

Fig. 17 illustrates the strong heterogeneity of the mechanical fields (here, the total dislocation density) that arises, both from packet to packet and inside packets, within the polycrystal when it is mechanically loaded. For the computation of local probabilities of fracture, the stresses are averaged over each finite element so that the numerical artefact related to pressure spatial oscillation between the Gauss point of a same elements vanishes. The fields used for post-treatments are thus described on the element level.

\section{Micromechanical local approach of failure}

In the literature, the terminology of "local approach" of failure classically refers to the methods that predict crack propagation from the local analysis of the stress and strain fields at the crack tip of a CT specimen. In our work, the material element which is considered in a classical local approach is a polycrystal whose behavior is described by a "micromechanical" (full-field) constitutive modelling instead of a macroscopical model. Since the basic building brick of the behaviour is a micromechanical model, the new qualifying term will be "micromechanical local approach". The output of this new approach on the material element provides, on the specimen (or component) scale, data which are valid for the classical (macroscopic) local approach. Additionnaly, it introduces a physical framework that gives a chance to description of the damage process such as microcracks activity within packets or grains (stop and go at packet boundaries, ...).

One can first take advantage of this method with the weakest link theory since the elementary links can be chosen to be either primary grains, bainite packets or ultimately finite elements. This theory considers the polycrystalline aggregate as a combination of $N$ independent sub-domains (primary grains, packets,...) in which the fracture of a single sub-domain causes the aggregate failure. With such conditions, the probability of fracture of the aggregate is simply $p=1-\prod_{i=1}^{N}\left(1-p_{i}^{s d}\right)$ where $p_{i}^{s d}$ is the probability of fracture of a sub-domain $i$. $p_{i}^{s d}$ is determined, as in [3; 4; 1], by means of the Griffith 
criterion:

$$
p_{i}^{s d}=\int_{0}^{\infty} p\left(\sigma_{l o c}>\sigma_{G}\right) \rho\left(\sigma_{G}\right) d \sigma_{G}
$$

where $p\left(\sigma_{l o c}>\sigma_{G}\right)$ is the probability that the local stress be superior to $\sigma_{G}$ and $\rho\left(\sigma_{G}\right) d \sigma_{G}$ is the probability to find $\sigma_{G}$ in the range $\left[\sigma_{G}, \sigma_{G}+d \sigma_{G}\right] . \sigma_{G}$ is the Griffith resistance, i.e. the critical stress above which cleavage occurs in crystallographic planes $\{001\}$. It is defined in eq. 5 in terms of the fracture energy $\gamma_{f}$, which is required for generating a new crack surface, and of the carbide size $a$ at an integration point, which is set according to a random distribution based on microstructural observations:

$$
\sigma_{G}=\frac{1}{2}\left[\frac{\pi E \gamma_{f}}{\left(1-v^{2}\right) a}\right]^{1 / 2} \quad E: \text { Young modulus; } \quad v: \text { Poisson coefficient }
$$

Alternatively, the assumption of serial fracture prevailing in the weakest link theory can be abandoned by considering that, due to microstructural barriers such as packet or grain boundaries, the fracture of a single domain of the aggregate could be unsufficient for causing the whole aggregate fracture, particularly if the broken link is a single packet among tens others within a same primary austenite grain. $\gg$ Such a scenario is justified by the observation of microcracks arrested at highly misoriented packets boundaries [6; 5] and can also be foreseen for explaining the phenomena of unstable crack propagation and arrest in ferritic steels [7, 8]. 44 To develop this notion of fracture induced by multiple microcracks, let us note $p_{I}^{p a c}$ the probability that $I$ packets and only $I$ be fractured. This probability is obtained from the analysis of the computed stresses (eq. 4). If we introduce $P_{I / g r}$, the probability that the fracture of $I$ packets leads to the fracture of their primary grain $j$, then the probability of fracture of grain $j$ reads:

$$
p_{j}^{g r}=\sum_{I=1}^{N_{p a c k}} p_{I}^{p a c} P_{I / g r} \quad \text { where } N_{\text {pack }} \text { is the number of packets in } j
$$

As a single primary grain $j$ can reasonably be considered to be at the origin of the aggregate fracture, and assuming further that its probability of fracture $p_{j}^{g r}$ depends only on the states of its packets, the probability of fracture of the aggregate becomes:

$$
p=1-\prod_{i=1}^{N_{g r}}\left(1-p_{j}^{g r}\right)
$$

For the application of this approach, values need to be set for $P_{I / g r}$. They should be deduced from microstructural observations. Still, it is possible to make a first analysis with remarkable $\gg$ realistic $\triangleleft 4$ values. Let us accept, $\rightarrow$ for the convenience of a simple analysis, $\triangleleft 4$ that $P_{I / g r}=1$ for $I \geq 4$. Then, as $\sum_{I=0}^{N_{p a c k}} p_{I}^{p a c}=1$ :

$$
p_{j}^{g r}=1-p_{0}^{p a c}-p_{1}^{p a c} \cdot\left(1-P_{1 / g r}\right)-p_{2}^{p a c} \cdot\left(1-P_{2 / g r}\right)-p_{3}^{p a c} \cdot\left(1-P_{3 / g r}\right)
$$

Attributing values taken from the set $(0,0.5,1)$ to $P_{1 / g r}, P_{2 / g r}$ and $P_{3 / g r}$ leads to the conclusion that $P_{1 / g r}$ is the parameter that, much more than the others, influences the prediction of fracture of the aggregate. This is illustrated in tab. 3 , in the case of a non irradiated material at $-90^{\circ} \mathrm{C}$, for $\gamma_{R}=14 \mathrm{Jm}^{-2}$ and at different stages of the plane strain tension with a triaxiality maintained at the value 2 . 


\begin{tabular}{|c|c|c|c|c|c|}
\hline \multirow[b]{2}{*}{$P_{1 / g r}$} & \multirow[b]{2}{*}{$P_{2 / g r}$} & \multirow[b]{2}{*}{$P_{3 / g r}$} & \multicolumn{3}{|c|}{ Equivalent deformation (\%) } \\
\hline & & & 2.5 & 5.0 & 7.5 \\
\hline 0 & 0 & 0 & 0.0443 & 0.3062 & 0.7135 \\
\hline 0 & 0 & 1 & 0.0443 & 0.3112 & 0.7150 \\
\hline 0 & 1 & 1 & 0.0444 & 0.3260 & 0.7196 \\
\hline 0.5 & 1 & 1 & 0.7041 & 0.9800 & 0.9995 \\
\hline 1 & 1 & 1 & 0.9184 & 0.9996 & 0.9999 \\
\hline
\end{tabular}

Table 1: Probability of failure of the aggregate (non irradiated material at $-90^{\circ} \mathrm{C}, \gamma_{R}=14 \mathrm{Jm}^{-2}$ (eq. 5 ), plane strain tension with a triaxiality maintained at the value 2)

\section{Conclusion}

This paper presents briefly a strategy for predicting fracture in bainite polycrystals at different temperatures and large strains. It is based on the condition that local packetto-packet interactions be well represented by the constitutive modelling. This imposes to have a high resolution microstructure with high quality element dicretization down to the intra-packets scale and to account for the main physical mechanisms involved in plastic straining and localization in BCC materials, namely the evolution of dislocation densities according to activation, annihilation, slip and hardening. Another condition for applying this strategy is the statistical representativity in terms of elementary heterogeneities, whose fractures are responsible for the fracture of the polycrystal. This is indeed required for capturing rare brittle fracture events, who are particularly under the concern of the nuclear industry. This is also required for the scenario of a material whose fracture is caused by multiple micro-fractures encountering microstructural barriers. A methodology has been proposed to address this problem, $\gg$ which can easily be extended to account for more specific micromechanisms involved in cleavage fracture, for example the influence of a microcrack on the probability of fracture in neighbouring packets. 44 All together, the full-field model and the methodology applied for determining fracture probabilities form a new micromechanical local approach of fracture in bainite polycrystals.

\section{References}

[1] N. Osipov, Génération et calcul de microstructures bainitiques, approche locale intragranulaire de la rupture, Ph.D. thesis, Ecole Nationale Supérieure des Mines de Paris (2007).

[2] N. Osipov, A. Gourgues-Lorenzon, B. Marini, V. Mounoury, F. N'Guyen, G. Cailletaud, FE modelling of bainitic steels using crystal plasticity, Phil Mag 88 (30) (2008) 3757-3777.

[3] J. Mathieu, K. Inal, S. Berveiller, O. Diard, A micromechanical interpretation of the temperature dependence of Beremin model parameters for french RPV steel, J Nuclear Materials 406 (2010) 97-112.

[4] M. Libert, C. Rey, L. Vincent, B. Marini, Temperature dependant polycrystal model application to bainitic steel behavior under tri-axial loading in the ductile-brittle transition, Int J Sol Struct 48 (2011) 2196-2208.

[5] A. Pineau, B. Tanguy, Advances in cleavage fracture modelling in steels: Micromechanical, numerical and multiscale aspects, C R Physique 11 (2010) 316-325.

[6] A. Lambert-Perlade, A. Gourgues, J. Besson, T. Sturel, A. Pineau, Mechanims and modelling of cleavage fracture in simulated heat-affected zone microstructure of a high strength low alloy steel, Metall Mater Trans A 35 (2004) 1039-1053.

[7] B. Prabel, S. Marie, A. Combescure, Using the X-FEM method to model the dynamic propagation and arrest of cleavage cracks in ferritic steel, Engng Fracture Mech 75 (2008) 2984-3009. 
[8] A. Bousquet, S. Marie, P. Bompard, Propagation and arrest of cleavage cracks in a nuclear pressure vessel steel during thermal shocks, in: 21st Int W Comput Mech Mater, Limerick (Ireland), 20-24 Aug., 2011.

[9] C. N. N'Guyen, Modélisation du comportement en plasticité et à rupture des aciers bainitiques irradiés, Ph.D. thesis, MINES Paristech (Feb. 4th 2010).

[10] R. Quey, P. Dawson, F. Barbe, Large-scale 3-D random polycrystals for the finite element method: Generation, meshing and remeshing, Comput Meth Appl Mech Engng 200 (2011) 1729-1745.

[11] J. Besson, R. Leriche, R. Foerch, G. Cailletaud, Object-Oriented Programming Applied to the Finite Element Method. Part II. Application to Material Behaviors, Revue Européenne des Éléments Finis 7 (5) (1998) 567-588. 